\title{
Assessment of Bronchodilator Response in Children with Asthma Exacerbation Using the Respiratory Resistance Values
}

\author{
Maria V. Bautista ${ }^{1}$, Jafar Vossoughi2 ${ }^{*}$, Arthur T. Johnson ${ }^{3}$, Martin Keszler ${ }^{4}$ \\ ${ }^{1}$ Division of Pediatric Pulmonary and Sleep Medicine, Medstar Georgetown University Hospital, Wisconsin Ave NW, \\ Washington, DC, USA \\ ${ }^{2}$ ESRA, Prospect Point Ct, Brookeville, MD, USA \\ ${ }^{3}$ Fischell Department of Bioengineering, University of Maryland, College Park, MD, USA \\ ${ }^{4}$ Department of Pediatrics, Alpert Medical School of Brown University, Women and Infants Hospital of Rhode Island, Providence, \\ RI, USA \\ Email: *vossoughi@verizon.net
}

How to cite this paper: Bautista, M.V., Vossoughi, J., Johnson, A.T. and Keszler, M. (2021) Assessment of Bronchodilator Response in Children with Asthma Exacerbation Using the Respiratory Resistance Values. Open Journal of Respiratory Diseases, 11, 117-132.

https://doi.org/10.4236/ojrd.2021.114011

Received: August 23, 2021

Accepted: September 25, 2021

Published: September 28, 2021

Copyright $\odot 2021$ by author(s) and Scientific Research Publishing Inc. This work is licensed under the Creative Commons Attribution International License (CC BY 4.0).

http://creativecommons.org/licenses/by/4.0/

(c) (i) Open Access

\begin{abstract}
Sixty-four pediatric patients with asthma exacerbation were studied. The children were subjected to respiratory resistance evaluation using the Airflow Perturbation Device (APD) and spirometry evaluation. They were then administered albuterol and 15 minutes later the APD and spirometry evaluations were repeated. Eleven of the children could not perform spirometry. The APD results demonstrated that respiratory resistance of the patients decreased by about $20 \%$, indicating that the APD could detect the expected response to bronchodilator. However, no similar conclusion could be made with the spirometry parameters (FVC, FEV1, FEV1/FVC, and FEF25\% - 75\%) performed on the same patients. The differences on the spirometry parameters did not change significantly before and after bronchodilator administration. Furthermore, these differences were negligibly increased or decreased for some with no consistency between the FVC, FEV1, FEV1/FVC, and FEF25\% - 75\%. Even though all the children were clinically improved after albuterol administration and discharged home, this could not be demonstrated by spirometry data. This study validates previous reports that spirometry is not a reliable pulmonary diagnostic tool for young children, as spirometry is highly effort-dependent and requires a substantial degree of patient cooperation. APD on the other hand is a reliable, simple, effortless diagnostic tool that can be utilized in evaluation and management of children with asthma symptoms and exacerbation.
\end{abstract}




\section{Keywords}

Pediatric Asthma, Respiratory Resistance, Spirometer, Albuterol

\section{Introduction}

Asthma is a common but complex respiratory disease characterized by airway hyper responsiveness and chronic inflammation. It is a potentially life-threatening illness that affects many adults and children of all ages. Asthma requires continuous attention by healthcare professionals for diagnosis and monitoring throughout the patient's lifetime. It is now accepted that much of the chronic persistent asthma in adulthood can be traced to childhood respiratory diseases [1] [2].

Asthma is the most common chronic respiratory disease and affects children more than adults [3] [4]; it currently affects 6.1 million children under the age of 8 years [5], and it is the most common chronic disease of all types in the United States [6].

Asthma disproportionately affects minorities, low-income inner-city populations with higher mortality and morbidity rates [7]-[14]. African American children are more likely to be hospitalized due to asthma complications compared to Caucasians and are four times as likely to die from asthma [8].

Asthma is the third leading cause of hospitalization among children under the age of 15 years [7]. Twenty four percent of children between the age of 5 to 17 have some limitation of activity due to asthma [6] [7]. In 2013, children with asthma between the age of 5 to 17 years old missed 15 million days of school [8] [9] [10] [11] [12]. Even mild asthma in children can interfere with child's ability to sleep, play, and participate at school [15] [16] [17] [18].

The Asthma in America survey of 1998 indicated that misunderstandings about asthma symptoms and treatment were widespread and that care often fell short of the National Asthma Education and Prevention guidelines [13]. More than 2 million children who suffer asthma attacks live in areas of the United States that received a failing grade for ozone levels by the American Lung Association [16].

The estimated cost of treating pediatric asthma is $\$ 3.2$ billion [19] [20]. Over $40 \%$ of all asthma hospitalizations are for children [20] and asthma in children is the cause of nearly five million physician visits and more than 200,000 hospitalization each year [21] [22].

A variety of Pulmonary function tests are used to diagnose asthma. The most popular diagnostic modality of asthma is the spirometric evaluation. Spirometry, although simple and inexpensive, it is not suitable for younger children. There are many reports describing the ineffectiveness of the spirometry in diagnosing asthma in children [23] [24] [25]. Peak flow meters are also simple and inexpensive screening tool but are also not suitable for younger children [26] [27]. Ple- 
thysmography and Impulse Oscillometry System (IOS) are used to diagnose respiratory disorders in adults and children, but they are expensive, are not portable and the data are difficult to interpret.

We have developed a simple, noninvasive, portable, effortless, and inexpensive respiratory diagnostic device, the Airflow Perturbation Device (APD), that in particular, is child friendly. The objective of this pilot study was to demonstrate the ability of APD to reliably measure changes in airway resistance following bronchodilator administration in young children with asthma exacerbation and compare the results to spirometry.

\section{Brief Description of the APD}

The Airflow Perturbation Device (APD) was initially developed as a simple, noninvasive, inexpensive, portable, and effortless respiratory diagnostic device for adults [28]-[34].

The APD measures resistance of the respiratory system by periodically inserting a known added resistance in the flow path by means of a rotating wheel with open and screened segments. The added resistance causes a slight decrease in airflow and a change in mouth pressure. The magnitudes of the flow and pressure perturbations depend on the relative resistance inside the patient's respiratory system and resistance of the APD itself. By measuring mouth pressure and airflow rate, with and without the APD resistance inserted into the path of the airflow, external resistance becomes known, and the internal respiratory resistance can easily be determined noninvasively. The resistance (in $\mathrm{cmH}_{2} \mathrm{O} / \mathrm{l} / \mathrm{s}$ ) is calculated by simply dividing the mouth pressure change, or perturbation, by the flow perturbation.

APD measurements were favorably compared with spirometry, body plethysmograph, and IOS in adults [35]-[40]. It was used in exercising subjects [41], and on subjects with paradoxical vocal fold motion [42] [43] [44] [45] [46]. The APD has also been used in a variety of other research projects, such as: Influence of nasal congestion on respiratory resistance [47]; testing low doses of caffeine on respiratory resistance [48]; comparison with esophageal balloon [49]; diurnal effects of respiratory resistance [50]; identification of patients with reactive airways [51]; optimization of airway caliber [52]; results using nasal strips [53]; and induced anxiety [54].

Figure 1 shows the current version of the hand-held APD and its interior (used to collect clinical data in the current study). It is small, weighing only 14.7 ounces. After use (set for 1 minute of continuous normal breathing) it immediately displays the respiratory resistance values (both in inhalation and exhalation phases separately) on its screen. Figure 2 shows a child using the APD. A nose clip can be used to measure respiratory resistance through the mouth, or an oronasal mask is used when the patient must breathe through the nose. A disposable antimicrobial filter (used in any PFT lab) is attached to the pneumotachometer of the APD while the subject uses the APD. 


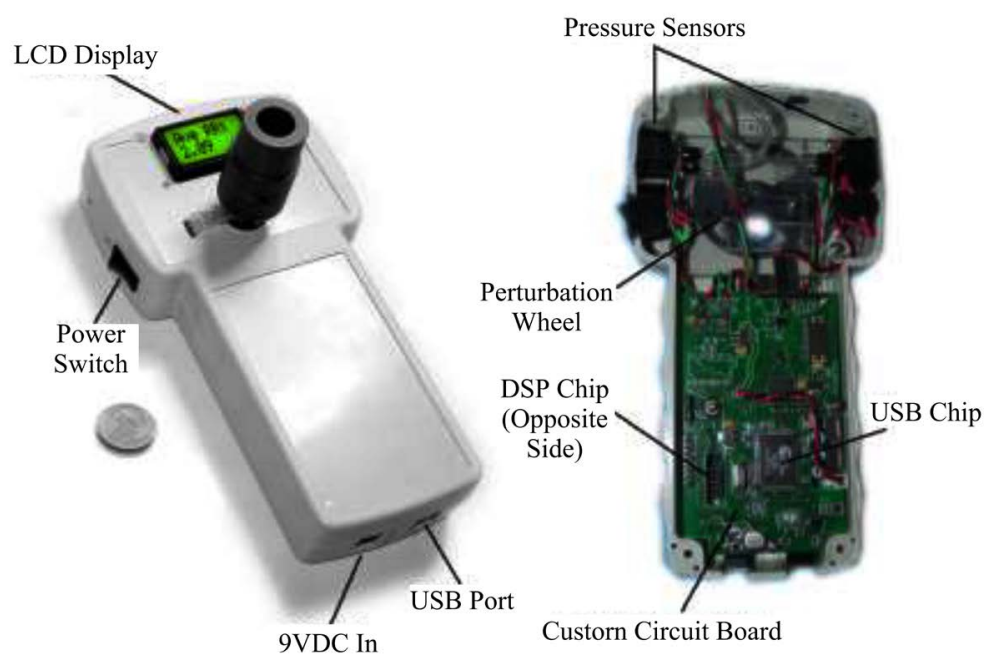

Figure 1. Current version of the Hand-Held APD with the pneumotachometer removed (left), with its cover removed to expose its interior (right).

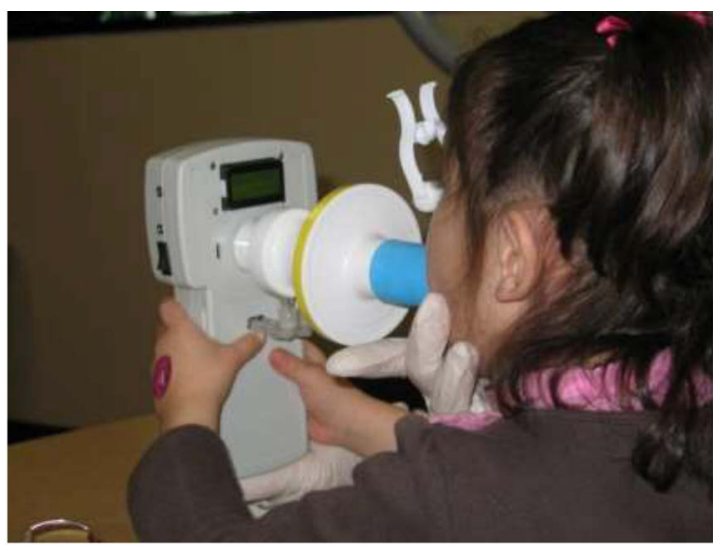

Figure 2. A child using the APD (with a nose clip and an antimicrobial filter).

The APD was originally designed as a respiratory diagnostic device for adults and children. To date we have collected respiratory resistance values of over 3500 subjects 2 to 88 years (Figure 3) [34], and recently the APD was successfully used to collect respiratory data on neonates.

As can be seen in Figure 3 respiratory resistance is highly age dependent, it is fairly high for young children (due to the smaller size of their airways) and decreases rapidly to a constant value in adulthood. Adult respiratory resistance values have been found to be bimodal, with women typically exhibiting higher resistance values than do men. The subjects used in the current investigation were in the group corresponding to the left portion of the resistance distribution curve that is highly age dependent, therefore, the values should be compared at the corresponding ages of the subjects.

Because the APD works simply as a subject breathes normally into the device it requires no special effort by the child, nor infant sedation, unlike spirometers that require considerable forceful effort and cooperation from the child. There- 
fore, it makes the APD an ideal respiratory diagnostic device for young children and infants.

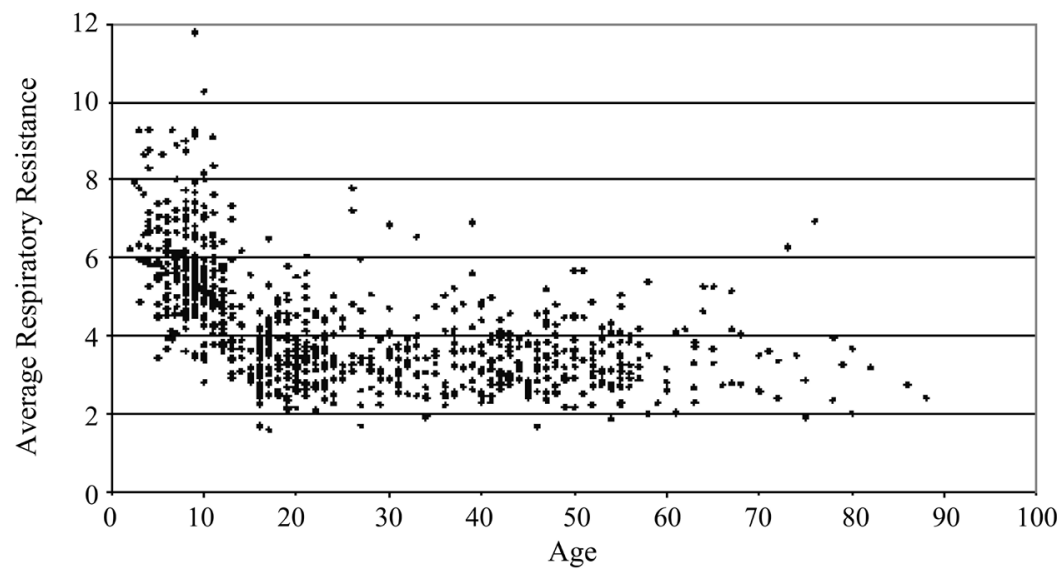

Figure 3. Average respiratory resistance $\left(\mathrm{cmH}_{2} \mathrm{O} / \mathrm{l} / \mathrm{s}\right)$ as a function of age (yr). [34].

\section{Methods}

A convenience sample of pediatric subjects who were brought to the Medstar Georgetown University Hospital outpatient pulmonology clinic due to asthma exacerbation was enrolled in the study. All subjects suffered from severe asthma flare-ups and manifested significant respiratory distress requiring urgent intervention.

\subsection{Inclusion/Exclusion Criteria}

Only subjects experienced severe asthma flareup with no other disorders were included. Subjects who were in imminent respiratory failure and required emergent admission were excluded. Table 1 shows the demographics of the subjects studied.

Table 1. Subjects demographics.

\begin{tabular}{cc}
\hline Total number of subjects & 64 \\
\hline Age range (years) & $5.6-17.9$ \\
(Mean \pm SD) & $(11.0 \pm 2.96)$ \\
Body weight range $($ Kg) & $19.6-94.4$ \\
(Mean \pm SD) & $(42.7 \pm 16.4)$ \\
Height range (cm) & $111.8-181.9$ \\
(Mean \pm SD) & $(144.2 \pm 15.3)$ \\
BMI range & $(13.9-32.3)$ \\
(Mean \pm SD) & $(19.8 \pm 4.1)$ \\
Male & 33 \\
Female & 31 \\
Caucasian & 29 \\
African America & 24 \\
Hispanic & 8 \\
Asian & 3
\end{tabular}




\subsection{Standard Care}

All subjects were administered a bronchodilator upon arrival (albuterol, standard dose of $2.5 \mathrm{mg}$ ). Before the bronchodilator administration each subject was asked to breathe into the APD as well as the spirometer. The data collected included the APD resistance values (average respiratory resistance, respiratory resistance in inhalation, and respiratory resistance in exhalation) and the values obtained from spirometry (Forced Vital Capacity (FVC), Forced Expiratory Volume in one minute (FEV1), FEV1/FVC ratio, and FEF25\% - 75\%) as well as the demographics and other pertinent clinical information. The subject's name was removed from the data sheet and a number was assigned to each data sheet. The study was approved by the Georgetown University Institutional Review Board, and, before data collection, signatures for the consent and/or assent forms were properly collected.

\section{Results}

A total of 64 children were enrolled. Their demographic and clinical characteristics are shown in Table 1. All subjects could use the APD successfully, but 11 of the children could not do spirometry.

Figure 4 shows the average respiratory resistance values for all 64 subjects before and after bronchodilator administration using the APD. Respiratory resistance decreased in all but 7 of the subjects after the bronchodilator administration, as expected. Seven of the subjects apparently did not respond to the bronchodilator application. This is also consistent with the claims of bronchodilator manufacturers that "not everyone will respond to the bronchodilator". To solidify this claim scientifically, Martinez, et al. [55] conducted an elaborate genetic study and illustrated genetic determinants of the responsiveness to albuterol by genotyping 269 children with asthma in a longitudinal study.

We removed the resistance values for these 7 subjects and to better see the changes to the respiratory resistance before and after bronchodilator application we curve-fit a polynomial to the resistance values before and after the bronchodilator application (Pre [Blue] and Post [Red] in the graph) (Figure 5). This shows, on average, an approximately $20 \%$ drop in the respiratory resistance values due to bronchodilator administration (Figure 5).

Figure 6 shows Forced Vital Capacity (FVC) values for all subjects before and after bronchodilator application. As mentioned earlier no spirometry data were obtained for 11 of the subjects because they could not perform spirometry. Similarly, we curve-fit a polynomial to the FVC values before and after bronchodilator application (Pre [Blue] and Post [Red] in the graph) (Figure 6). There was no noticeable change in the FVC values before and after bronchodilator administration. In assessing the effectiveness of the bronchodilator treatment, we can conclude that the spirometry data of the FVC are inconclusive. Note that there was no correlation between those who did not respond to the bronchodilator (increased respiratory resistance in the APD evaluation) with increased/ decreased FVC. 


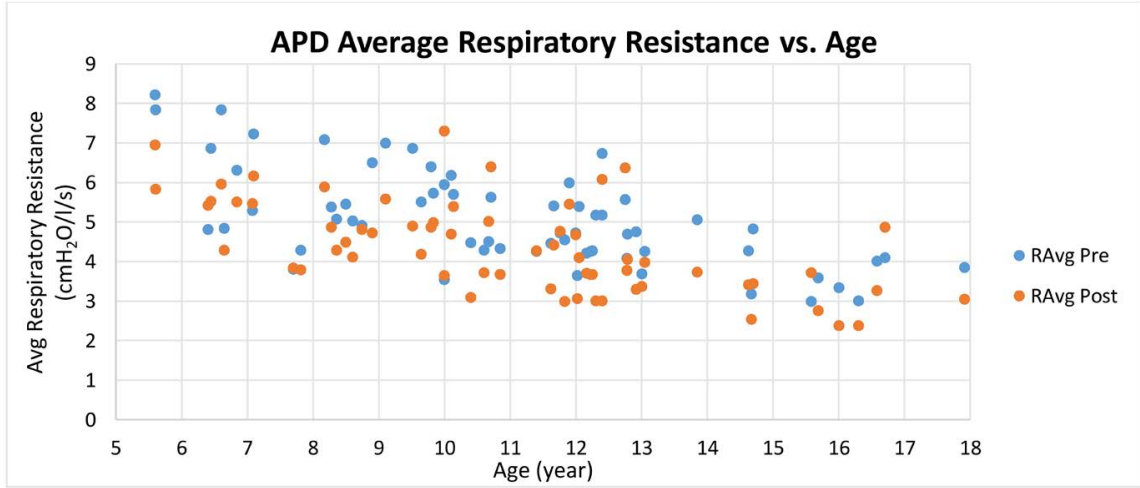

Figure 4. Average respiratory resistance values (in $\mathrm{cmH}_{2} \mathrm{O} / \mathrm{l} / \mathrm{s}$ ) vs. age (Yr.) obtained using the APD on 64 severely asthmatic children, pre (blue)- and post (red)-bronchodilator administration.

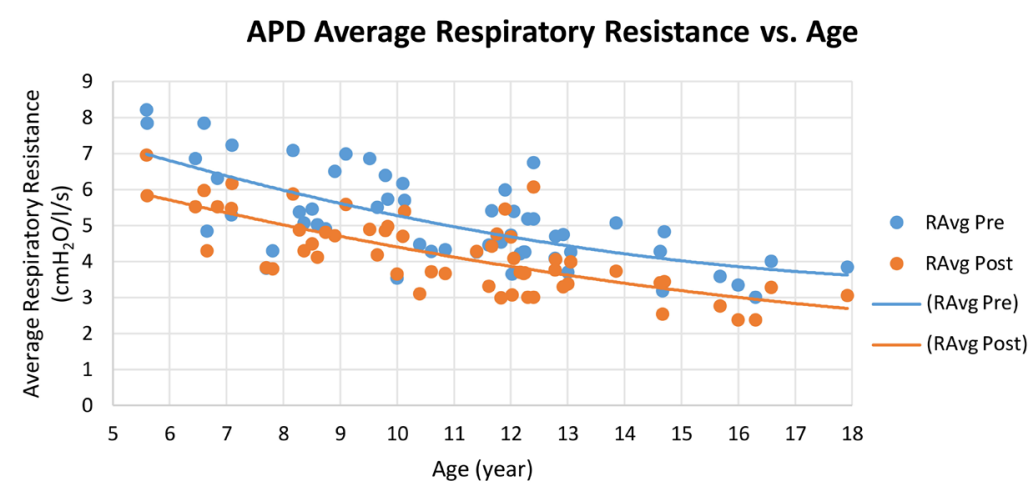

Figure 5. Average respiratory resistance values (in $\mathrm{cmH}_{2} \mathrm{O} / \mathrm{l} / \mathrm{s}$ ) vs. age (Yr.) obtained using the APD on 57 severely asthmatic children who showed a response to bronchodilator, pre (blue)- and post (red)-bronchodilator administration. A polynomial curve fit to the data is shown.

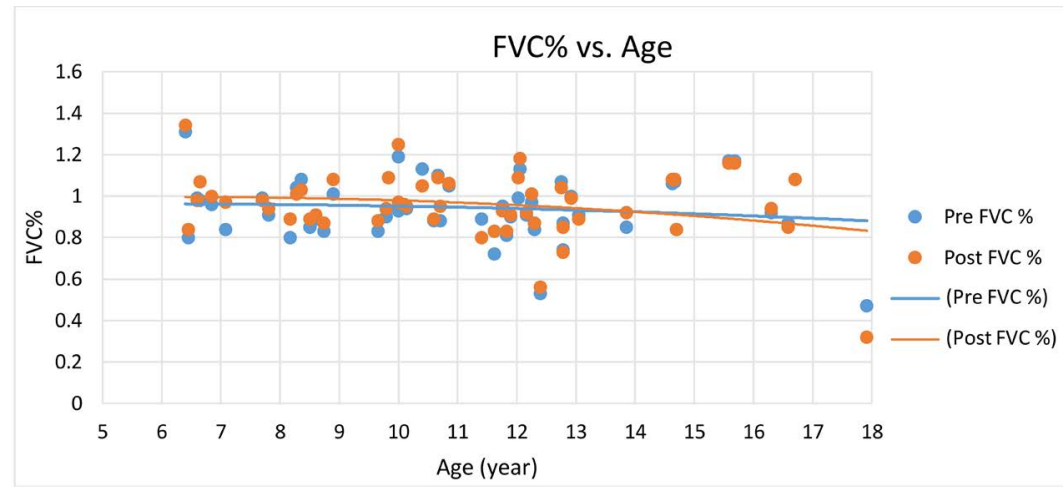

Figure 6. Percent Forced Vital Capacity (FVC\%) vs. age (Yr.) of 53 severely asthmatic children who were able to perform spirometry pre (blue)- and post (red)-bronchodilator administration.

Figure 7 shows Forced Expiratory Volume in one minute (FEV1) for all subjects who could perform spirometry before and after bronchodilator application. There was no significant change in the FEV1 values before and after bronchodi- 
lator administration. We can conclude that the spirometry data of the FEV1 are inconclusive.

Figure 8 shows FEV1/FVC values for all subjects who could perform spirometry before and after bronchodilator application. Similarly, the changes in FEV1/ FVC before and after bronchodilator administration were insignificant. We can conclude that the spirometry data of the FEV1/FVC are also inconclusive.

We also examined the FEF25\% - 75\% values for all 53 subjects before and after bronchodilator application. Figure 9 shows FEF25\% - 75\% (1/s) vs. subject age and as can be seen, overall, there is no significant difference for the FEF25\% $75 \%$ values before and after the bronchodilator administration.

To see the spirometry values for each subject, see the bar-diagrams shown in Figures 10-13 illustrating spirometry data before and after bronchodilator administration for each individual child. In these diagrams each set of two consecutive bars is associated with one subject, pre (blue)- and post (red)-bronchodilator administration. Comparing two values of each FVC, FEV1, FEV1/FVC, and FEF25\% - 75\% for each subject shows very small change with no clear pattern (increase/decrease) before and after bronchodilator administration. This

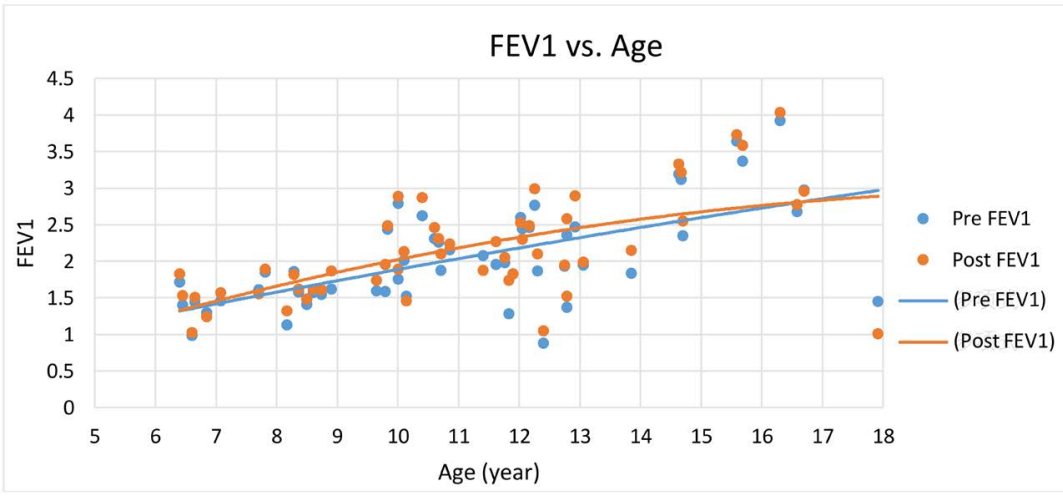

Figure 7. Forced Expiratory Volume in one minute (FEV1) vs. age (Yr.) of 53 (11 out of 64 could not perform spirometry) severely asthmatic children pre (blue)- and post (red)bronchodilator administration.

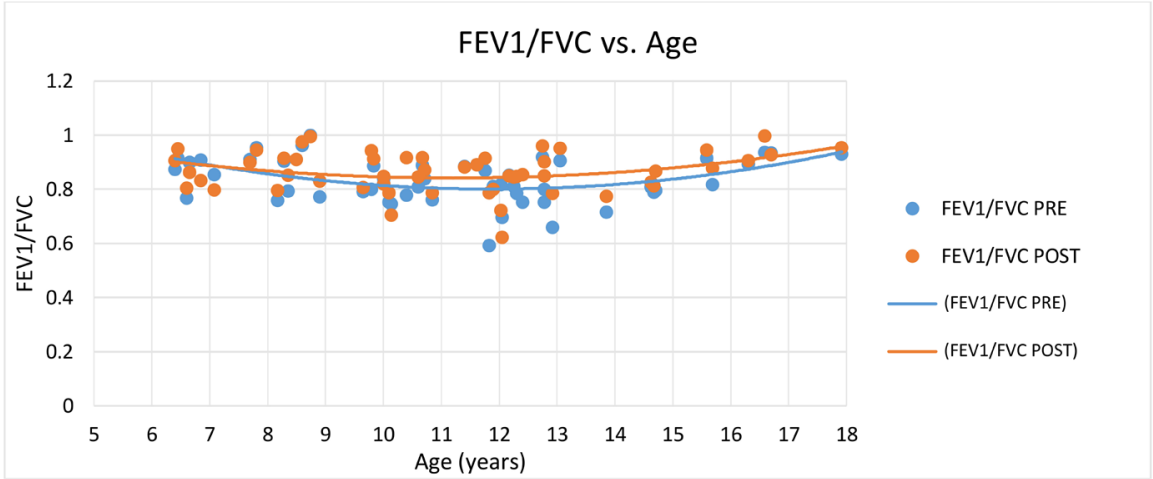

Figure 8. The FEV1/FVC values (FEV1/FVC) vs. age (Yr.) of 53 (11 out of 64 could not perform spirometry) severely asthmatic children pre (blue)- and post (red)-bronchodilator administration. 


\section{FEF25-75\% PRE POST vs. Age}

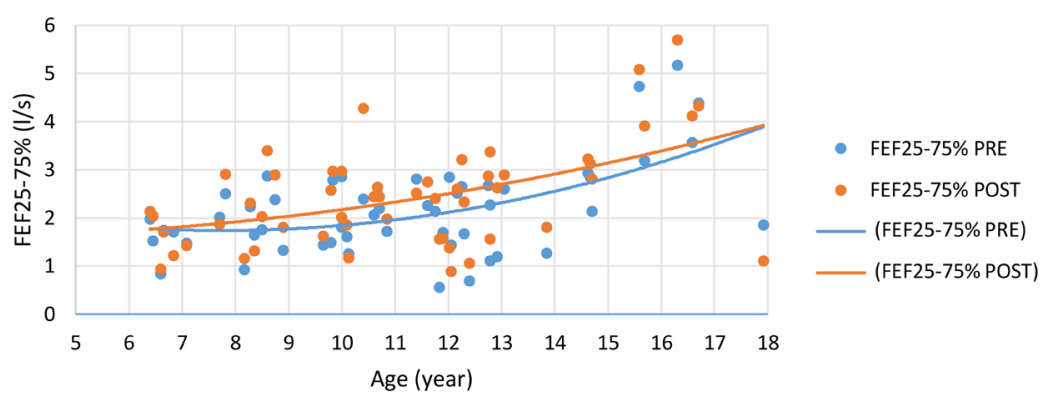

Figure 9. Values of FEF25\% - 75\% (1/s) for each subject before and after bronchodilator application (pre (blue)- and post (red)-bronchodilator administration). As can be seen the differences are mostly insignificant.

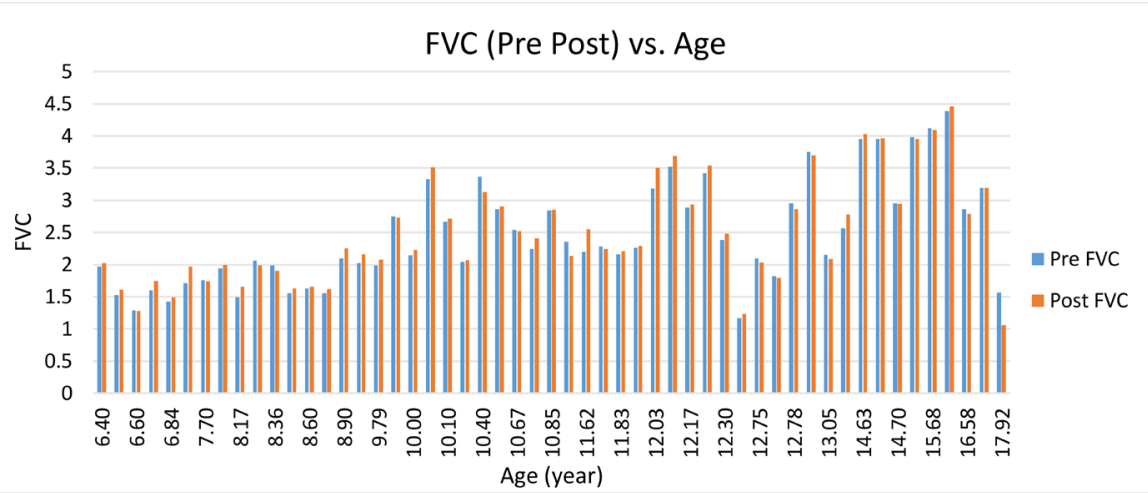

Figure 10. Values of FVC for each subject before and after bronchodilator administration (pre (blue)- and post (red)-bronchodilator administration). As can be seen the differences are mostly insignificant.

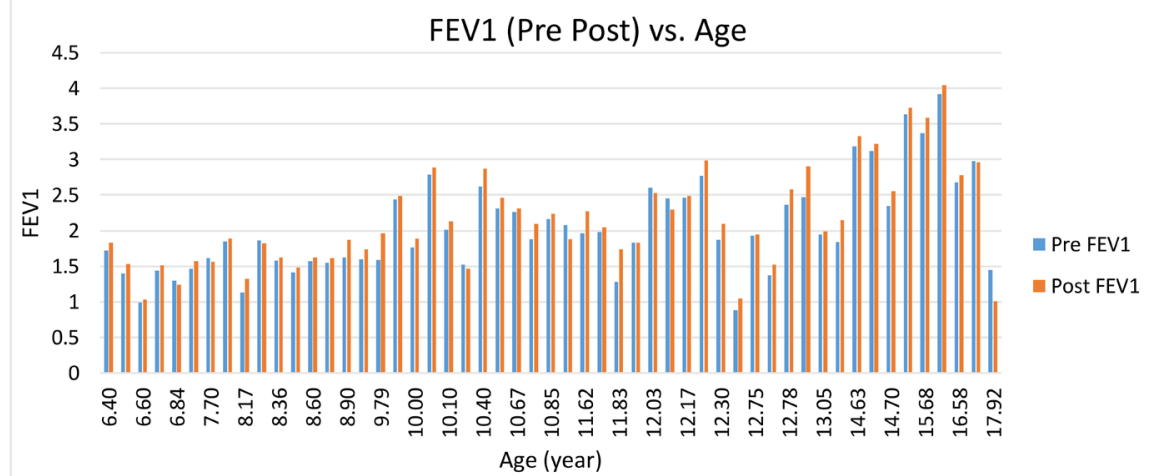

Figure 11. Values of FEV1 for each subject before and after bronchodilator administration (pre (blue)- and post (red)-bronchodilator administration). As can be seen the differences are mostly insignificant.

clearly shows that spirometry values, at least for asthmatic children studied in this work, are inconclusive.

Similarly, to visualize the FEF25\% - 75\% values before and after bronchodilator administration for each individual child, we have looked at the bar-diagram 


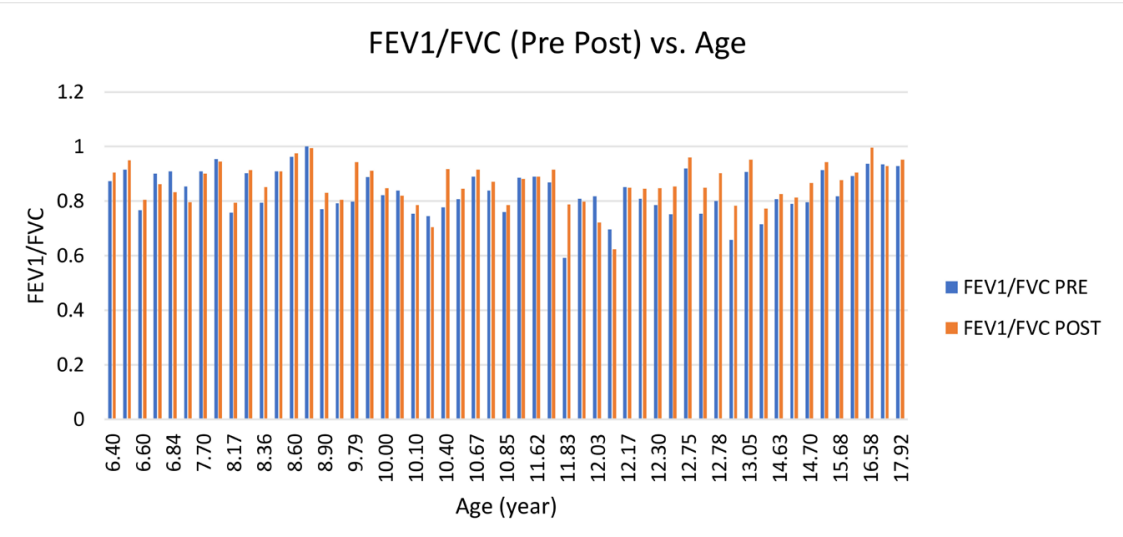

Figure 12. Values of FEV1/FVC for each subject before and after bronchodilator administration (pre (blue)- and post (red)-bronchodilator administration). As can be seen the differences are mostly insignificant.

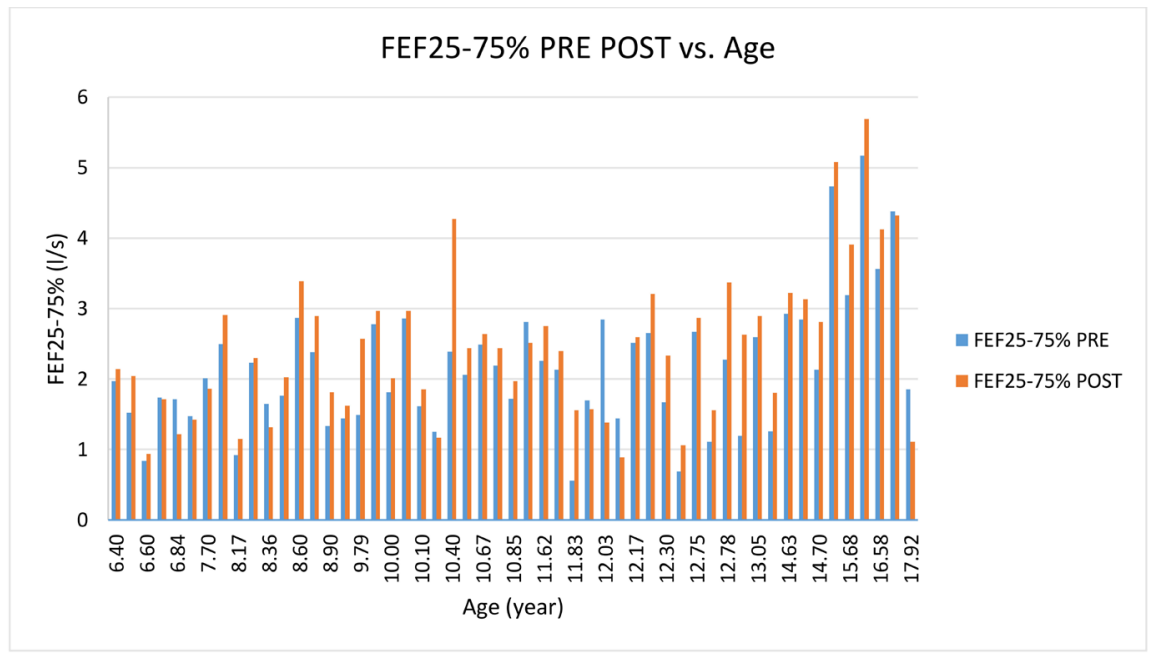

Figure 13. Values of FEF25\% - 75\% (1/s) for each subject before and after bronchodilator application (pre (blue)- and post (red)-bronchodilator administration). As can be seen, overall, the differences are mostly inconclusive.

shown in Figure 13. In this diagram each set of two consecutive bars is associated with one subject, pre (blue)- and post (red)-bronchodilator administration. Comparing the two values of FEF $25 \%$ - 75\% for each subject show very small change (increase/decrease) before and after bronchodilator administration. The changes, although not consistently increased/decreased, are, however, larger than those for FVC and FEV1 shown in Figures 10-12. This clearly shows that spirometry values, at least for asthmatic children studied in this work, are inconclusive.

It is interesting to note that it is well known and also demonstrated here (Figure 5) that the respiratory parameters are function of age, but we cannot see this for spirometry values (FVC, FEV1, FEV1/FVC, and FEF25\% - 75\%). This, most probably, can be attributed to the lack of sensitivity of the spirometry, and the fact that spirometry requires a proper cooperation of the subject, which like- 
ly did not consistently occur in these children.

\section{Statistical Analysis}

Although the curves in Figure 5 show a clear difference between the respiratory resistance values before and after albuterol administration and not so for the curves in Figures 6-9, we conducted statistical analysis to solidify this. We applied a few statistical analysis methods to the data, and all showed that the respiratory resistance values were significantly different before and after albuterol administration, this was supported by a very small p-value of 3.32E-7 in paired $\mathrm{t}$-test, indicating the before and after values are highly statistically significantly different. The p-vales for the spirometry data (Figure 6, Figure 7, and Figure 9) were very large $(0.295,0.092$, and 0.075$)$; for Figure 8 the p-value was 0.027 . This may indicate that among the 4 spirometry parameters (FVC, FEV1, FEV1/ FVC, and FEF25\% - 75\%) studied the FEV1/FVC may be a better spirometry indicator, this however needs to be shown using much larger number of subjects. We also used Wilcoxson and Cohen statistics and they also indicated that the data in Figure 5 were very strong significantly different, but not significantly different for spirometry parameters.

\section{Discussion}

This study is the first to demonstrate the ability of the APD to detect the response to bronchodilator in children with acute asthma symptoms. The baseline results showed high airway resistance values in 64 children experiencing asthma flare-ups. Post-bronchodilator measurements showed significant decline in the airway resistance in majority of the children reflecting the anticipated response to albuterol. The measured fall in airway resistance was consistent with observed clinical improvement. In contrast, spirometry revealed no significant difference in the values of the FVC, FEV1, FEV1/FVC, and FEF25\% - 75\% before and after administration of albuterol in these children despite symptomatic improvement after bronchodilator administration, likely because of suboptimal ability to perform spirometry. The results indicate that measurement of airway resistance using an APD is a more sensitive indicator of response to bronchodilator than spirometry in children who present with airway obstruction from asthma. This pilot study suggests that the APD may be a useful tool for monitoring of asthma status and response to therapy in young children who are unable to effectively perform spirometry. Furthermore, measurement of the airway resistance using the APD in children with asthma can be early indicator of any impeding asthma flare-up and can, therefore, guide clinicians with early intervention using albuterol to prevent worsening respiratory exacerbation and subsequent hospitalization.

This pilot study is an initial proof-of concept evaluation of this device in children. Each subject acted as his/her own control, which is an important strength of the study. However, the number of subjects is relatively small and spans a large 
age and size span. The study was not designed or powered to detect gender differences or other factors that may affect the response to bronchodilators. Further studies are needed in the pediatric population to elucidate some of these factors and the APD may prove to be an excellent tool to carry out such studies, because of its ease of use in very young children who are unable to cooperate with standard spirometry.

This clearly demonstrates the advantage of using the respiratory resistance compared to spirometry parameters in asthmatic children.

\section{Conclusion}

This study has shown that APD is easy to use by young children with significant respiratory symptoms and can provide an objective assessment of the response to albuterol treatment.

\section{Acknowledgements and Disclosures}

This work was partially supported by the NIH Grant HL078055 (JV). The authors declare that there is no conflict of interests.

\section{Authors' Contributions}

Maia Bautista, Jafar Vossoughi, Arthur Johnson, and Martin Keszler contributed to the study conception and design; Maria Bautista and Jafar Vossoughi contributed to the subject data collection; Jafar Vossoughi and Arthur Johnson conducted the data analysis; all four authors contributed to the manuscript preparation and editing.

\section{Conflicts of Interest}

The authors declare no conflicts of interest regarding the publication of this paper.

\section{References}

[1] Martinez, F.D. (2009) The Origins of Asthma and Chronic Obstructive Pulmonary Disease in Early Life. Proceedings of the American Thoracic Society, 6, 272-277. https://doi.org/10.1513/pats.200808-092RM

[2] Martinez, F.D. (2011) New Insights into Natural History of Asthma: Primary Prevention on the Horizon. Journal of Allergy and Clinical Immunology, 128, 939-945. https://doi.org/10.1016/j.jaci.2011.09.020

[3] National Survey of Children's Health. NSCH 2011/12. Data Query from the Child and Adolescent Health Measurement Initiative. http://childhealthdata.org/browse/survey

[4] American Lung Association (2004) Asthma in Children Fact Sheet.

[5] Centers for Disease Control and Prevention. National Center for Health Statistics. National Health Interview Survey, 2016. https://www.cdc.gov/nchs/nhis/index.htm

[6] Wang, L.Y., Zhong, Y. and Wheeler, L. (2005) Direct and Indirect Cost of Asthma in School-Age Children. Preventing Chronic Disease, 2, A11. 
[7] Centers for Disease Control and Prevention. National Center for Health Statistics. National Hospital Discharge Survey, 1995-2010.

https://www.cdc.gov/nchs/nhds/index.htm

[8] Mannino, D., et al. (2002) Surveillance of Asthma-United States, 1980-1999. Morbidity and Mortality Weekly Report, 51, 1-13.

[9] Centers for Disease Control and Prevention. Behavioral Risk Factor Surveillance Survey, 2015. https://www.cdc.gov/brfss/index.html

[10] Asthma Facts and Figures. Allergy and Asthma Foundation of America, Washington DC. http://www.aafa.org/page/asthma.aspx

[11] Wirt, J., Choy, S., Gerald, D., et al. (2001) Condition of Education: 2001. National Center for Education Statistics, U.S. Department of Education, Washington DC.

[12] National Center for Environmental Health, Centers for Disease Control and Prevention (2005) Asthma's Impact on Children and Adolescents. Atlanta.

https://www.cdc.gov/asthma/children.htm

[13] Mayrides, M. (2005) Ethic Disparities in the Burden and Treatment of Asthma. Allergy and Asthma Foundation of America and the National Pharmaceutical Council, Washington DC.

http://www.aafa.org/media/Ethnic-Disparities-Burden-Treatment-Asthma-Report.p df

[14] Clark, N.M., Brown, R., Joseph, C.L.M., et al. (2002) Issues in Identifying Asthma and Estimating Prevalence in an Urban School Population. Journal of Clinical Epidemiology, 55, 870-881. https://doi.org/10.1016/S0895-4356(02)00451-1

[15] Weiss, K.B. and Wagener, D.K. (1990) Asthma Surveillance in the United States. A Review of Current Trends and Knowledge Gaps. Chest, 98, 179S-184S. https://doi.org/10.1378/chest.98.5 Supplement.179S

[16] (1999) Asthma and Respiratory Diseases. Children's Environmental Health Network, Washington DC. http://www.cehn.org

[17] Merkle, S., Wheeler, L.S., Gerald, L.B., et al. (2006) Introduction: Learning from Each Other about Managing Asthma in Schools. Journal of School Health, 76, 202-204. https://doi.org/10.1111/j.1746-1561.2006.00096.x

[18] Taras, H. and Potts-Datema, W. (2005) Childhood Asthma and Student Performance at School. Journal of School Health, 75, 296-312. https://doi.org/10.1111/j.1746-1561.2005.tb07347.x

[19] Weiss, K.B., Sullivan, S.D. and Lyttle, C.S. (2000) Trends in the Cost of Illness for Asthma in the United States, 1985-1994. Journal of Allergy and Clinical Immunology, 106, 493-499. https://doi.org/10.1067/mai.2000.109426

[20] Wang, L.Y., Zhong, Y. and Wheeler, L. (2005) Direct and Indirect Costs of Asthma in School-Age Children. Preventing Chronic Disease, 2, A11.

[21] (2000) National Hospital Discharge Survey. National Center for Health Statistics, Hyattsville. https://www.cdc.gov/nchs/nhds/index.htm

[22] Akinbami, L.J. (2006) State of Childhood Asthma, United States, 1980-2005. Advance Data from Health and Vital Statistics, No. 381, 1-24. https://www.cdc.gov/nchs/data/ad/ad381.pdf

[23] Gaffin, J.M., Lichtenberg Shotola, N., Martin, T.R. and Phipatanakul, W. (2010) Clinically Useful Spirometry in Preschool-Aged Children: Evaluation of the 2007 American Thoracic Society Guidelines. Journal of Asthma, 47, 762-767. https://doi.org/10.3109/02770903.2010.485664

[24] Meneghini, A.C., Paulino, A.C.B., Pereira, L.P. and Vianna, E.O. (2017) Accuracy of 
Spirometry for Detection of Asthma: A Crosssectional Study. Sao Paulo Medical Journal, 135,428-433. https://doi.org/10.1590/1516-3180.2017.0041250517

[25] Yang, C.L., Simons, E., Foty, R.G., Subbarao, P., To, T. and Dell, S.D. (2017) Misdiagnosis of Asthma in Schoolchildren. Pediatric Pulmonology, 52, 293-302.

https://doi.org/10.1002/ppul.23541

[26] Miller, M.R. (1996) Potential Problems in Peak Expiratory Flow Data Used to Diagnose Occupational Asthma. Occupational Medicine, 46, 230-241. https://doi.org/10.1093/occmed/46.3.239

[27] Miller, M.R. and Ouanjer, P.H. (1994) Peak Flow Meters: A Problem of Scale. BMJ Clinical Research, 308, 548-549. https://doi.org/10.1136/bmj.308.6928.548

[28] Lausted, C.G. and Johnson, A.T. (1999) Respiratory Resistance Measured by an Airflow Perturbation Device. Physiological Measurement, 20, 21-35. https://doi.org/10.1088/0967-3334/20/1/002

[29] Johnson, A.T., Lin, C.S. and Hochheimer, J.N. (1984) Airflow Perturbation Device for Measuring Airways Resistance of Humans and Animals. IEEE Transactions on Biomedical Engineering, 31, 622-626. https://doi.org/10.1109/TBME.1984.325306

[30] Silverman, N.K., Johnson, A.T., Scott, W.H. and Koh, F.C. (2005) Exercise-Induced Respiratory Resistance Changes as Measured with the Airflow Perturbation Device. Physiological Measurement, 26, 29-38. https://doi.org/10.1088/0967-3334/26/1/003

[31] Vossoughi, J., Johnson, A.T. and Silverman, N.K. (2006) In-Home Hand-Held Device to Measure Respiratory Resistance. Distributed Diagnosis and Home Healthcare, Arlington, 2-4 April 2006, D2H2, 12-15.

[32] Johnson, A.T., Scott, W.H., Russek-Cohen, E., Koh, F.C., Silverman, N.K. and Coyne, K.M. (2007) Resistance Values Obtained with the Airflow Perturbation Device. International J of Medical Implants and Devices, 2, 45-58.

[33] Lopresti, E.R., Johnson, A.T., Koh, F.C., Scott, W.H., Jamshidi, S. and Silverman, N.K. (2008) Testing Limits to Airflow Perturbation Device (APD) Measurements. BioMedical Engineering Online, 7, 28. https://doi.org/10.1186/1475-925X-7-28

[34] Shade, D.M. and Johnson, A.T. (2010) Design of Respiratory Devices. In: Kutz, M., Ed., Standard Handbook of Biomedical Engineering and Design, 2nd Edition, McGraw-Hill, New York, 111-142.

[35] Goldman, M.D., Lemert, J., Vossoughi, J., Johnson, A., Silverman, N. and Saadeh, C.K. (2006) Airflow Perturbation Device Reflects Forced Oscillation Indices of Peripheral Airway Obstruction. Chest. https://doi.org/10.1378/chest.130.4 MeetingAbstracts.160S-e

[36] Lemert, J., Goldman, M.D., Johnson, A., Vossoughi, J., Silverman, N. and Saadeh, C.K. (2006) Portable Hand-Held Airflow Perturbation Device Reflects Forced Oscillation Resistance in Children with Asthma. Chest. https://doi.org/10.1378/chest.130.4 MeetingAbstracts.241S-c

[37] Whitesell, P., Whitesell, J., Vossoughi, J. and Johnson, A. (2012) Comparison of Airflow Perturbation Device and Impulse Oscillometry Measurements of Airway Resistance. Chest. https://doi.org/10.1378/chest.1388780

[38] Haque, T., Vossoughi, J., Johnson, A.T., Bell-Farrell, W., Fitzgerald, T. and Scharf, S.M. (2013) Resistance Measured by Airflow Perturbation Compared with Standard Pulmonary Function Measures. Journal of Respiratory Diseases, 3, 63-67. https://doi.org/10.4236/ojrd.2013.32010

[39] Holley, A.B., Boose, W.D., Perkins, M., Sheikh, K.L., Solomon, N.P., Dietsch, A.M., Vossoughi, J., Johnson, A.T. and Collen, J.F. (2018) A Rapid, Handheld Device to 
Assess Respiratory Resistance: Clinical and Normative Evidence. Military Medicine, 183, e370-e377. https://doi.org/10.1093/milmed/usx224

[40] Pan, J., Saltos, A., Smith, D., Johnson, A. and Vossoughi, J. (2013) Comparison of Respiratory Resistance Measurements Made with an Airflow Perturbation Device with Those from Impulse Oscillometry. Journal of Medical Engineering, 2013, Article ID: 165782. https://doi.org/10.1155/2013/165782

[41] Johnson, A.T., Chapain, P., Slaughter, D., Gallena, S. and Vossoughi, J. (2013). Inspiratory and Expiratory Resistances during Exercise. British Journal of Medicine \& Medical Research, 3, 1222-1232. https://doi.org/10.9734/BJMMR/2013/2409

[42] Gallena, S.K., Tian, W., Johnson, A.T., Vossoughi, J., Sarles, S.A. and Solomon, N.P. (2013) Validity of a New Respiratory-Resistance Measurement Device to Detect Glottal-Area Change. Journal of Voice, 27, 299-304. https://doi.org/10.1016/j.jvoice.2013.01.006

[43] Gallena, S.K., Solomon, N.P., Johnson, A.T., Vossoughi, J. and Tian, W. (2014) Effect of Exercise on Athletes with and without Paradoxical Vocal Fold Motion Disorder. American Journal of Speech-Language Pathology, 24, 470-479.

https://doi.org/10.1044/2015 AJSLP-14-0110

[44] Gallena, S.K., Solomon, N.P., Johnson, A.T., Vossoughi, J. and Tian, W. (2014) TestRetest Reliability of Respiratory Resistance Measured with the Airflow Perturbation Device. Journal of Speech, Language, and Hearing Research, 57, 1323-1329. https://doi.org/10.1044/2014 JSLHR-S-13-0246

[45] Gallena, S.K., Johnson, A.T. and Vossoughi, J. (2018) Short-Term Intensive Therapy and Outcomes for Athletes with Paradoxical Vocal Fold Motion Disorder. The American Journal of Speech-Language Pathology, 28, 1-13. https://doi.org/10.1044/2018 AJSLP-17-0223

[46] Solomon, N.P., Pham, A., Gallena, S., Johnson, A.T., Vossoughi, J. and Faroqi-Shah, Y. (2020) Resting Respiratory Resistance in Female Teenage Athletes with and without Exercise-Induced Laryngeal Obstruction. Journal of Voice, 9/2. https://doi.org/10.1016/j.jvoice.2020.09.002

[47] Awowale, A., Johnson, A. and Vossoughi, J. (2015) Influence of Nasal Congestion on Respiratory Resistance Values. Journal of Pulmonary \& Respiratory Medicine, 5, 228. https://doi.org/10.4172/2161-105X.1000228

[48] Montgomery, M.K., Luk, A., Johnson, A.T. and Vossoughi, J. (2017) Testing Low Doses of Caffeine on Respiratory Resistance Using the Airflow Perturbation Device. Open Journal of Respiratory Diseases, 7, 53-61.

https://doi.org/10.4236/ojrd.2017.72006

[49] Coursey, D.C., Scharf, S.M. and Johnson, A.T. (2011) Comparison of Expiratory Isovolume Pressure-Flow Curves with the Stop-Flow Versus the Esophageal-Balloon Method. Respiratory Care, 56, 969-975. https://doi.org/10.4187/respcare.01037

[50] Rausch, N.Z., Johnson, A.T. and Vossoughi, J. (2018) Diurnal Effects of Respiratory Resistance Using an Airflow Perturbation Device. Archives of Pulmonology, 1, 41 48.

[51] Patel, S.U., Rosen, R., Johnson, A.T. and Vossoughi, J. (2018) Identification of Patients with Reactive Airways at Ambient Temperatures. Archives of Pulmonology, 1, 23-29.

[52] Johnson, A.T., Jones, S.C., Pan, J.J. and Vossoughi, J. (2012) Variation of Respiratory Resistance Suggests Optimization of Airway Caliber. IEEE Transactions on Biomedical Engineering, 59, 2355-2361. https://doi.org/10.1109/TBME.2012.2204055

[53] Wong, L.S. and Johnson, A.T. (2004) Decrease of Resistance to Air Flow with Nasal 
Strips as Measured with the Airflow Perturbation Device. BioMedical Engineering OnLine, 3, 38. https://doi.org/10.1186/1475-925X-3-38

[54] Bohensky, M., Johnson, A.T. and Vossoughi, J. (2017) Effect of Induced Anxiety on Respiratory Resistance Using Virtual Reality Simulation. Open Journal of Respiratory Diseases, 7, 68-82. https://doi.org/10.4236/ojrd.2017.72008

https://www.scirp.org/journal/paperinformation.aspx?paperid $=76455$

[55] Martinez, F.D., Graves, P.E., Baldini, M., Solomon, S. and Erickson, R. (1997) Association between Genetic Polymorphisms of the b2-Adrenoceptor and Response to Albuterol in Children with and without a History of Wheezing. Journal of Clinical Investigation, 100, 3184-3188. https://doi.org/10.1172/JCI119874 